\title{
Instrumental e comunicativo no ensino de línguas: mesma abordagem, nomes diferentes? ${ }^{1}$
}

\section{ESP / LSP and communicative in language teaching: same approach, different names?}

Elaine Ferreira do Vale Borges*

Universidade Federal de Minas Gerais

RESUMO: $\mathrm{O}$ uso dos termos abordagem comunicativa e abordagem instrumental tem sido recorrente no contexto brasileiro. Isso gera dúvidas quanto a serem abordagens diferentes ou nomes diferentes para uma mesma abordagem. Este artigo objetiva expor a compreensão que se tem dessas concepções nos contextos nacional e internacional de ensino de línguas. Atenção também será dada ao termo abordagem comunicacional. Serão explicitadas e discutidas as principais publicações da área sobre o tema, iniciando em Palmer (1917) e incluindo depoimentos de especialistas de renome, como Widdowson e Prabhu - coletados em 2006 -, culminando em Borges (2009). Este artigo chama a atenção para um "afrouxamento" no tratamento de um tema que se mostra um contexto profícuo para a compreensão do surgimento e desenvolvimento de paradigmas e metaparadigmas na Linguística Aplicada

PALAVRAS-CHAVE: comunicativo, instrumental, abordagem de ensino de língua.

ABSTRACT: The use of the terms communicative approach and ESP/LSP approach has been recurrent in the Brazilian context. This raises doubts as to whether they are different approaches or different names for the same approach. This paper aims at highlighting the current understanding regarding those conceptions both in international and Brazilian language teaching contexts. Attention is also given to the term communicational approach. This work underlines and discusses the leading publications on this subject, starting with Palmer (1917), including the testimony of renowned experts such as Widdowson and Prabhu - collected in 2006 -, and culminating with Borges (2009). This article draws attention to a "relaxation" in the treatment of a theme that unfolds as an appropriate context fo

* elainefvb@uol.com.br. Pós-doutoranda da Faculdade de Letras. Fundação de Amparo à Pesquisa de Minas Gerais. Belo Horizonte - Minas Gerais / Brasil.

${ }^{1}$ Agradeço à CAPES e ao Programa de Intercâmbio Internacional da USP e Programa Santander, pelo apoio financeiro. 
$r$ the comprehension of the emergence and development of paradigms and metaparadigms in Applied Linguistics.

KEYWORDS: communicative approach, ESP/LSP approach, teaching language approach.

\section{Introdução}

Neste artigo, objetivo mostrar e comentar a compreensão de importantes especialistas brasileiros e estrangeiros (e a minha em particular), no cenário de ensino e aprendizagem de línguas estrangeiras (LEs) e segunda língua (L2), sobre o instrumental e o comunicativo. O que coloco em questão para reflexão é a autonomia do instrumental em relação ao comunicativo como abordagem de ensino de língua. Por outro lado, porém com menos destaque, por já ter tratado dessa questão específica em outro trabalho (BORGES, 2010b), abordarei também o comunicacional de forma autônoma em relação ao comunicativo. Tudo isso tendo em vista que a visão recorrente na área, principalmente no contexto brasileiro, é a de que: a) o instrumental constitui-se como parte integrante da abordagem comunicativa ou é a própria; b) o termo comunicacional é sinônimo do termo comunicativo, sinalizando a evolução da abordagem comunicativa na contemporaneidade.

As diferenças entre o instrumental, o comunicativo e o comunicacional como abordagens distintas entre si foram amplamente discutidas em Borges (2009; 2010a), mas as retomo resumidamente aqui para melhor contextualização dessa discussão. A abordagem comunicativa (para fins gerais) desenvolveu-se a partir da visão de competência comunicativa de Hymes (1972) e dos estudos de Widdowson $(1972,1978 / 1991)$ que destacou as regras de uso de uma LE / L2 como extensão das regras da gramática dessa mesma língua, o que acaba por permitir a explicitação do sistema gramatical da língua em sala de aula quando assim se fizer necessário. O chamado English for Specific Purposes precede o surgimento da abordagem comunicativa, tendo Hutchinson e Waters (1987) como os mais influentes expoentes dessa concepção. No Brasil, o termo abordagem instrumental aparece em Ramos (2005), mas Celani (1997) já havia usado o termo abordagem de ensino de línguas para fins específicos. Segundo Ramos, os princípios definidores da abordagem instrumental são: aprendizagem centrada no aprendiz; levantamento de necessidades dos alunos como norte do planejamento de cursos; temas e conteúdos dos cursos relacionados às áreas de atuação dos alunos. Pelo viés mais pragmático dessa última concepção, já amplamente denominada de abordagem no Brasil (embora 
mantendo uma visão implícita de sinônimo de abordagem comunicativa), o seu foco é no desenvolvimento da competência pragmática ou na habilidade para $o$ uso da língua em contextos específicos. O termo abordagem comunicacional (para fins gerais) é cunhado por Prabhu (1987). Esse linguista aplicado indiano propõe uma pedagógica de ensino diferente da (e oposta à) já enfatizada pela abordagem comunicativa, visando o ensino de língua através da comunicação (e não para a comunicação), com atividades focadas no significado e sem quaisquer explicitações do sistema da língua, já que esse sistema é reconhecido como uma predisposição inata do aprendiz. A visão de competência gramatical, em Prabhu, foco de sua abordagem, difere da visão dessa mesma competência inserida na definição de competência comunicativa de Hymes (1972).

Com base no exposto acima, vou iniciar as reflexôes no presente artigo com uma explicitação (e alguns comentários) da evolução histórica no que diz respeito à compreensão do instrumental, do comunicativo e do comunicacional em várias publicaçôes da área para que se comprove a necessidade de tal discussão. Esse contexto histórico inicia-se com os estudos de Palmer (1917 / 1968; 1921 / 1964) e culmina com a pesquisa de Borges (2009). Em seguida, exponho os depoimentos de especialistas brasileiros e estrangeiros sobre a provável (ou não) divisão entre o comunicativo e o instrumental (e o comunicacional, com menos ênfase, mas não com menos importância). Os referidos depoimentos, que mostram uma visão mais atualizada da discussão, foram coletados no ano de 2006 via e-mail / internet - com autorizaçóes dos envolvidos para a sua plena divulgação -, realizada durante o desenvolvimento da pesquisa de Borges (2009).

A reflexão proposta neste artigo finaliza-se com as minhas próprias considerações sobre esse "debate", caminho percorrido pelas pesquisas que venho desenvolvendo até o momento. "Debate" que não se esgota neste artigo. Provavelmente as colocaçóes dispostas aqui explicitem apenas uma pequena parte submersa do iceberg que protagoniza a "confusão" e / ou o "afrouxamento" com que é tratado pelos especialistas da área o tema em questão, comprometendo, muito provavelmente, a formaçoes de professores de línguas e de especialistas na área de Linguística Aplicada.

A título de esclarecimento, utilizo o termo comunicativo para me referir à abordagem comunicativa (para fins gerais) e / ou ensino comunicativo e não ao movimento comunicativo, para o qual uso a sigla MC. Da mesma forma, o uso do termo instrumental refere-se à abordagem instrumental (para fins específicos) e / ou ensino instrumental; e o termo comunicacional (para fins gerais) faz alusão à abordagem comunicacional e / ou ensino comunicacional. 
Considero que o instrumental, o comunicativo e o comunicacional, como abordagens independentes entre si, compõem o MC (BORGES, 2009). O termo movimento em Borges é interpretado como um paradigma sociológico (KUHN, 1962/2001) que abriga, como um conjunto, diferentes metaparadigmas (MASTERMAN, 1979) ou subconjuntos (abordagens). No contexto de ensino de línguas, isso equivale a dizer que o movimento subentende uma visão de linguagem em sentido macro, como no caso da linguagem como ato social ou como comunicação do $\mathrm{MC}$; e as abordagens constituem-se por diferentes visões de linguagem em sentido micro e, consequentemente, por diferentes concepções do processo de aquisição de língua, como a visão de linguagem como processo (de comunicação), como instrumento (de comunicação) e como esforço cognitivo (de comunicação) da abordagem comunicativa, instrumental e comunicacional, respectivamente. Essa visão de Borges será retomada ao longo do artigo por meio de reflexões e comentários sobre as obras e depoimentos apresentados e irá compor também, ao lado das visões dos outros especialistas destacados, o QUADRO 1 (apresentado ao final do primeiro tópico).

\section{Um pouco de contexto histórico e alguns comentários}

Palmer (1917 / 1968; 1921 / 1964) talvez tenha sido um dos primeiros estudiosos da linguagem a destacar uma possível diferença entre um ensino de línguas para fins específicos (instrumental) e um ensino de línguas para fins gerais (comunicativo e, atualmente, o comunicacional) ao enfatizar questôes relativas à capacidade de estudo e à capacidade espontânea dos aprendizes. Ideia retomada depois por Krashen (1976; 1981 / 2002), ao usar os termos aprendizagem e aquisição, respectivamente (CELANI, 1997).

Wilkins (1976) classifica três tipos de planejamentos para o ensino de línguas estrangeiras, a saber: planejamento gramatical, planejamento situacional ${ }^{2} \mathrm{e}$

${ }^{2}$ O planejamento situacional (WILKINS, 1976) não deve ser confundido como o método situacional ou com o que Richards e Rogers (2001) denominam ensino situacional de lingua. Estes se referem ao uso concreto de "figuras e objetos educativos que juntos com açôes e gestos podem ser usados para demonstrar os significados dos novos itens da língua” (op. cit. p. 43). Salimbene (1983, p. 3) esclarece que o método situacional "usa contextos significativos para apresentar estruturas gramaticais" e faz parte de um planejamento gramatical; já o "planejamento situacional considera a língua num contexto social e 'é baseado em prediçōes da situação em que o aprendiz é provável de operar através da língua estrangeira”. 
planejamento nocional, dos quais os dois últimos são os que mais interessam à discussão deste artigo. Segundo o autor, um planejamento situacional deve prever situaçōes de necessidades de uso e aplicação da língua-alvo do aprendiz e ensiná-la de forma que o aprendiz possa desenvolver-se linguística e comunicativamente nessas situaçôes específicas. Um planejamento nocional objetiva, com mais ênfase do que no situacional, o uso da língua-alvo para a comunicação, preocupando-se, assim, com o desenvolvimento da capacidade do aprendiz para se comunicar efetivamente na língua-alvo, independentemente do contexto e/ou da situação de uso.

As visōes de Palmer e Wilkins já sinalizam diferenças fundamentais entre o instrumental e o comunicativo. Palmer se converte em um precursor importante desses dois contextos, mas principalmente do instrumental, ao demonstrar, bem antes de sua formalização, preocupações com as diferentes necessidades dos alunos principalmente no campo profissional, embora esse autor ainda se encontrasse preso a preocupaçōes mais em termos descritivos da língua do que do uso efetivo da linguagem. Wilkins, em uma linha mais nocional-funcional, contribui igualmente, ao discutir tipos diferentes de planejamentos de cursos de ensino de LE / L2. Todavia, éo planejamento nocional que acaba ganhando maior visibilidade na área.

Howatt (1984; 1988, p. 25-6) traz uma divisão entre o que classifica como versão forte e versão fraca da abordagem comunicativa. Na primeira, ao termo comunicativo estaria subentendido que "o ato de comunicação é uma pré-condiçãoo necessária para a aquisição de uma língua"; "3 já na segunda, a condição necessária para a aprendizagem de uma língua seria "aprender e aperfeiçoar um conjunto de habilidades". O autor coloca que nessa divisão entre versōes forte e fraca tem-se o que Krashen (1981 / 2002) enfatizou como aquisição e aprendizagem e o que Brumfit (1984) descreveu como fluência e precisão. Prabhu (1987), inserido na versão forte, de acordo com Howatt, teria preferido o uso do termo comunicacional ao comunicativo. Howatt destaca ainda que subjacente à sua interpretação de versão fraca estaria uma teoria de aprendizagem behaviorista - só que um behaviorismo mais relaxado, neoskinneriano ${ }^{4}$ (em contraste com uma visão neochomskyana da versão forte). Mas as colocaçōes de Howatt geram algumas dúvidas, como discutido a seguir.

\footnotetext{
${ }^{3}$ Esta e outras traduções são de minha responsabilidade.

${ }^{4}$ Inserido nesse neoskinnerianismo, como compreendo, estão alguns tipos de visão behaviorista que pretendem inserir noções relativas ao contexto cognitivo dos aprendizes, promovendo uma relação mais estreita entre o social e as questóes da mente. Entre essas visóes tem-se o que se classifica como behaviorismo social e behaviorismo cognitivo, por exemplo.
} 
Inicialmente, pode-se compreender que a versão forte em Howatt seria o comunicativo (no que esse contexto subentende o comunicacional - visão incorporada no contexto brasileiro) e a versão fraca seria o instrumental. Nesse quadro, teríamos duas abordagens dentro do MC (a comunicativa / comunicacional e a instrumental). Todavia, o autor parece compreender o instrumental e o comunicativo como compondo um "todo" - a que denomina de abordagem comunicativa, ensino comunicativo ou MC (aqui subentendendo uma noção de movimento como sinônimo de abordagem). Por essa perspectiva, teríamos apenas uma abordagem (a comunicativa / instrumental / comunicacional) no $\mathrm{MC}$ - sendo que essa abordagem acabaria se confundindo com o próprio movimento, tornando abordagem comunicativa e MC como sinônimos entre si. Notadamente, Howatt e Widdowson (2004) confirmam que o "pacote" completo do $\mathrm{MC}$, ou seja, as noçôes de abordagem comunicativa e competência comunicativa (HYMES, 1972) - sendo que esta última acaba dando nome ao movimento e à abordagem - tornaram-se sinônimos de ensino comunicativo. $\mathrm{E}$, ao que tudo indica, as concepções de comunicacional e instrumental também acabaram compondo o "pacote" e, por vezes, assumindo a noção de sinônimos de ensino comunicativo (abordagem e movimento) e, consequentemente, subentendendo também a noção de competência comunicativa hymesiana. Contudo, o que Howatt aparenta querer separar é o comunicacional (versão forte) do comunicativo / instrumental (versão fraca).

A reflexão ainda se complica um pouco quando Howatt enfatiza que o sentido de comunicação no comunicacional (versão forte) não tem nada a ver com o sentido proposto pelo comunicativo (versão fraca), questão já enfatizada anteriormente. Nesse contexto, o autor pode estar se referindo a sua visão da evolução da abordagem comunicativa que, por carregar o mesmo significado de movimento (que considero um erro), vai de uma interpretação fraca de comunicação para uma interpretação forte. Mas isso, de acordo Borges (2009; 2010a), não parece ser a evolução de uma mesma coisa (de uma abordagem que é sinônimo de movimento), mas, sim, uma ruptura de fundamentação importante dentro do MC (que não é sinônimo de abordagem comunicativa) que toma a comunicação (ou a linguagem como ato social) como mote. Essa ruptura pode mostrar o surgimento de outra abordagem (além da comunicativa e da instrumental) dentro do MC como a abordagem comunicacional.

Além disso, tendo em mente a definição de abordagem de Anthony (1963, p. 8) para o contexto de ensino de línguas como "um conjunto de suposiçōes correlatas tratando da natureza da linguagem e da natureza do ensino-aprendizagem", pode-se concluir que as versōes forte e fraca em Howatt 
são abordagens diferentes e não versões (forte e fraca) de uma mesma abordagem; já que um viés neoskinneriano difere no que se refere à natureza da linguagem e da aprendizagem de um viés neochomskyano (sendo que um viés não se converte na versão fraca ou forte do outro). Ainda, consideradas as características da abordagem comunicativa (de base hymesiana), que rejeitam tanto a visão skinneriana quanto a chomskyana, é difícil imaginar que o comunicativo "aceite" tomar para si características neoskinnerianas ou neochomskyanas. Essas características parecem "servir" melhor ao instrumental (neoskinneriano) e ao comunicacional (neochomskyano).

Waters (1993), discutindo especificamente o contexto do EIFE, ${ }^{5}$ destaca um "buraco" entre teoria e prática no desenvolvimento dessa visão de ensino de línguas ou entre o que o autor sugere como o paradigma clássico do EIFE (que surge em 1970 e vai até 1980); e como segunda era do EIFE (que surge a partir de 1990, estendendo-se até os dias atuais). Nesse sentido, de acordo com o autor, seriam os praticantes do EIFE, ou seja, os próprios professores de línguas, que, a partir de 1990, estariam desviando o EIFE de suas raízes originais, reinventando uma prática desfocada da teoria que lhe deu origem. Na visão do autor, passa a existir a necessidade de uma reformulação teórica que responda por essa prática. Compreendo, aqui, que o problema destacado por Waters talvez se deva ao fato de que os professores de línguas estariam tentando aplicar o instrumental em sala de aula, baseados em uma teoria que faz parte do comunicativo (como ora proposto nos $\mathrm{PCN}-\mathrm{LE}^{6}$ ), o que acarretaria no desvio entre teoria e prática (cf. BORGES, 2003) destacado por Waters. O paradigma clássico do EIFE, citado pelo autor, é o que entendo como instrumental; e o que o ele classifica como segunda era do EIFE é o que tomo como comunicativo.

Complicando ainda mais a reflexão, Richards (1990 apud CELCEMURCIA; DORNYEI; THURRELL, 1997) divide explicitamente o ensino comunicativo em duas abordagens (e não em versões de uma mesma abordagem, como o faz Howatt): uma indireta e outra direta. A primeira é um tipo de abordagem "em que a competência conversacional é vista como um produto de engajamento do aprendiz em interação conversacional". A segunda é um tipo de abordagem que "envolve o planejamento de um programa conversacional ao redor de micro-habilidades específicas, estratégias, e processos que estão envolvidos em conversação fluente" (p. 141).

\footnotetext{
${ }^{5}$ Ensino de Inglês para Fins Específicos - tradução de English for Specific Purposes (ESP).

${ }^{6}$ Parâmetros Curriculares Nacionais de Língua Estrangeira - Ensino Fundamental.
} 
Celce-Murcia, Dornyei e Thurrell (1997, p. 146) retomam a visão de Richards de duas abordagens (uma direta e outra indireta) no ensino comunicativo, mas as interpretam de forma diferente. Para os/as autores/as, a abordagem indireta é uma abordagem presente na prática de ensino típica do ensino comunicativo dos anos de 1970 e 1980 e a abordagem direta - que se manifesta a partir dos anos de 1990 - é entendida como uma reação à primeira (a abordagem indireta), ou melhor, "como uma virada no ensino comunicativo".

Essa visão em Celce-Murcia et al., no que se refere às divisões de data, parece similar a de Waters (1993). O que permite dizer que a abordagem indireta poderia corresponder ao paradigma clássico do EIFE e que a abordagem direta corresponderia à segunda era do EIFE. No entanto, essa correspondência de datas - que aproxima as visōes em Waters e Celce-Murcia et al. - parece não corresponder exatamente ao que Celce-Murcia et al. se referem como abordagem indireta e direta. Celce-Murcia et al. dão a entender que ocorre uma divisão de abordagens que vai além do EIFE discutido em Waters. Isso devido ao fato dos / as autores / as pontuarem o que denominam de virada no ensino comunicativo, que sugere que a abordagem indireta estaria relacionada aos contextos do instrumental e do comunicativo juntos (e não só ao contexto do instrumental como em Waters) - constituindo, assim, instrumental e comunicativo, uma mesma abordagem (a versão fraca em Howatt).

Em relação à virada no ensino comunicativo, pode-se pensar no desenvolvimento do comunicacional (a versão forte em Howatt). Conforme Celce-Murcia et al. (1997, p. 147), a passagem de uma abordagem comunicativa indireta para uma direta mostra um processo de mudança de um desenvolvimento cíclico natural no contexto de ensino de línguas em que novos estudos ${ }^{7}$ sobre os processos de ensino-aprendizagem e de aquisição de língua são incorporados. Dessa forma, o comunicativo encontrar-se-ia num momento de virada, ou seja, "elementos diretos e explícitos estão se tornando significativos para o ensino de habilidades e capacidades comunicativas"; emergindo, assim, uma nova abordagem que é descrita pelos autores como principled communicative approach. ${ }^{8}$ Essa nova

\footnotetext{
${ }^{7}$ Os / as autores / as citam os avanços e resultados de pesquisas nos seguintes campos: análise do discurso oral, análise da conversação, pesquisas em competência comunicativa, análise de interlíngua, análise de insumo, sociolinguística, psicologia cognitiva, e antropologia.

${ }^{8}$ Optei pela não tradução, mas corresponderia a algo como abordagem comunicativa que tem princípios em uma tradução livre.
} 
abordagem - que entendo ser a comunicacional - seria a abordagem direta, só que reformulada com a assimilação dos avanços conquistados nos novos estudos citados.

Contrário às colocaçôes de Celce-Murcia et al. e em resposta ao artigo discutido no parágrafo anterior, Thornbury (1998, p. 110) enfatiza que a abordagem indireta se relaciona com a abordagem de versão forte em Howatt (1984) e a abordagem direta com a de versão fraca - confirmando, aqui, a relação feita previamente por mim entre as visões de Richards e de Howatt. Para Thornbury, o ensino comunicativo nunca deixou de ser uma abordagem direta (ou seja, a versão fraca de Howatt), e a versão forte (a abordagem indireta), com exceção "de seu momento de glória em Bangalore (PRABHU, 1987), tem sido e perdura uma quimera". Assim, Thornbury parece salientar que o que a literatura da área enfatiza por abordagem comunicativa, $\mathrm{MC}$ ou ensino comunicativo (sinônimos entre si) continua atualmente com os mesmos princípios que lhe deram origem, sem quaisquer alteraçóes. Incluindo, aqui, o instrumental e excluindo o comunicacional (que perdura uma quimera).

Widdowson (1998), por sua vez, enfatiza práticas de ensino de LEs e L2 para fins de aprendizagem e para fins de uso (ou para fins especificos e para fins gerais, respectivamente, em minha interpretação). A primeira com característica de "treinamento" e com preocupaçôes mais profissionais, e a segunda com características de "educação" e com preocupações mais pedagógicas. Também, enfatizando o contexto específico do EIFE - como o faz Waters (1993) - o autor traz uma divisão entre o que classifica de "inglês de negócios" e "inglês para negócios", sendo o primeiro usado e custodiado pelos nativos, e o segundo pela comunidade internacional. Essa divisão é importante na medida em que ressalta a diferença do uso de LEs / L2 em ambientes de trabalho (instrumental) e em outros ambientes não relacionados diretamente à profissão (comunicativo e comunicacional). Nesse aspecto, o instrumental "preocupa-se" com a aquisição de LE / L2 para sanar prováveis necessidades advindas dos ambientes profissionais do aprendiz.

Em Howatt e Widdowson (2004), Howatt parece mudar um pouco sua visão ao citar que o Projeto Bangarole de Prabhu (comunicacional) não compartilha as noções funcionais / nocionais do comunicativo; sendo esse o motivo pela opção de Prabhu pelo uso do termo comunicacional - essa seria a mesma posição defendida pelo próprio Prabhu em seu livro de 1987, em que o autor esclarece as bases teóricas, conquistas e resultados de seu projeto. Howatt e Widdowson ainda enfatizam que, enquanto o ensino comunicativo está envolvido em aspectos mais relacionados à sociolinguística, a visão de 
Prabhu está mais relacionada à psicolinguística (e a reflexões da linguística póschomskyana). Sem mencionar, contudo, se essas duas visões poderiam ser consideradas, por esse motivo, abordagens distintas. Os autores, agora, apenas classificam o comunicativo, em relação à visão de Prabhu, como ortodoxo dando margem à interpretação segundo a qual o comunicacional poderia ser classificado como um ensino comunicativo não-ortodoxo.

No panorama nacional, Almeida Filho (2004) considera que o comunicativo / comunicacional (sinônimos entre si) compartilha um paradigma (marca macro) reflexivo, em oposição a outros, quais sejam: o aristotélico ou skinneriano e o platônico. O comunicativo / comunicacional também é classificado, pelo autor, como um paradigma (macro-filosofia) de ensino de língua em oposição a outro, o ensino gramatical. $O$ autor se refere também a duas grandes abordagens como sendo a sistêmico-gramatical e a interativo-comunicacional. Num trabalho anterior, Almeida Filho (1998, p. 8) destacou ainda que o ensino comunicativo se apresenta atualmente "com várias faces, as quais poderíamos dispor num contínuo que vai desde o falso comunicativo até o ultra comunicativo ou comunicativo espontaneísta, passando pelo comunicativo funcionalizado, comunicativo inocente e comunicativo progressista”. Já Cardoso (2002) - que parece seguir a mesma linha de Almeida Filho - apresentou cinco versões da abordagem comunicativa, quais sejam: ensino apropriado (planejamento nocional-funcional de Wilkins, 1976), foco na mensagem (baseado em WIDDOWSON, 1978), visão psicolinguistica do processamento da linguagem (fundamentado nos estudos de HALLIDAY), abordagem comunicativa padrão e técnicas de prática livres ou holistica.

A visão que nos passa Almeida Filho parece ser a de que o comunicativo / comunicacional é uma abordagem única que evoluiu em suas reflexões e, consequentemente, em sua denominação (de comunicativa para comunicacional ou intercambiando os dois termos na referência a uma mesma abordagem). A impressão que fica também é a de que essa abordagem é sinônimo de MC - o "pacote" já destacado em Howatt e Widdowson (2004) e discutido acima. Igualmente, a noção de abordagem comunicativa em Cardoso nos passa a noção da existência de um "todo", um "pacote" (a própria abordagem comunicativa), que se constitui de versóes em sua evolução. Entendo que o que evoluiu foi o MC (o paradigma sociológico, o conjunto) no desenvolvimento de suas diferentes abordagens (metaparadigmas, subconjuntos), quais sejam: a comunicativa, a instrumental, a comunicacional e outras que possivelmente 
forem surgindo dentro dos pressupostos previstos no MC e / ou de sua visão de linguagem em sentido macro como ato social.

Ramos (2005) usa explicitamente o termo abordagem instrumental e situa seu surgimento com o contexto histórico do pós-segunda guerra, época em que a literatura da área considera o início do MC. Ao citar o aparecimento dessa abordagem no Brasil, em 1970, a autora comenta que por essa época o audiolingualismo encontrava-se no seu auge e a abordagem comunicativa no seu início. Na mesma linha de pensamento, Celani (1997) já havia utilizado o termo abordagem de ensino para fins específicos e pontuado não ser fácil constatar quem havia surgido primeiro: a abordagem de ensino para fins específicos ou a abordagem comunicativa. Percebe-se, aqui, que Celani divide o instrumental e o comunicativo como abordagens distintas ou, pelo menos, vale-se da utilização de dois nomes diferentes utilizando o termo abordagem em cada um. Holmes e Celani (2006), por sua vez, denominam o ensino de língua para fins específicos no Brasil ora como ESP methodology, ora como Brazilian / Latin approach.

Voltando a Waters (1993), expoente importante do EIFE, esse autor considera que o paradigma clássico do EIFE surge a partir de 1970, época que, segundo Ramos, surge a abordagem comunicativa. Interpreto que o que Waters considera como o paradigma clássico do EIFE é o que Ramos considera ter surgido na época do pós-segunda guerra, ou seja, a abordagem instrumental (essa abordagem é que seria o paradigma clássico do EIFE). Já a abordagem comunicativa, em Ramos, que surge a partir de 1970, é possivelmente o que Waters considera tanto como paradigma clássico quanto a segunda era do EIFE; ou seja, o que Waters divide em seu artigo e interpreta como sendo o instrumental (clássico e segunda era) parece ser o que a área entende como o todo chamado de comunicativo (abordagem e movimento), que surge a partir de 1970. Isso não está em acordo com a visão de Ramos, respaldada por publicaçôes na área, de que o instrumental surge no contexto de pós-segunda guerra e como consequência das demandas desse contexto (principalmente na área profissional). Nesse sentido, entendo que é o instrumental que preconiza o MC que, por sua vez, é o contexto de surgimento da abordagem comunicativa (e, posteriormente, da abordagem comunicacional).

O QUADRO 1 é uma tentativa de visualização resumida de todas as considerações enfatizadas neste tópico sobre o instrumental, o comunicativo e o comunicacional, iniciando-se em Palmer (1917/1968; 1921/1964) e culminando em Borges (2009; 2010a). 


\section{QUADRO 1}

Resumo da evolução histórica das consideraçôes de diferentes especialistas na área de ensino de línguas sobre o instrumental, o comunicativo e o comunicacional

\begin{tabular}{|c|c|c|c|}
\hline & INSTRUMENTAL & COMUNICATIVO & COMUNICACIONAL \\
\hline Palmer $(1917,1921)$ & capacidade de estudo & capacidade espontânea & \\
\hline$\hookrightarrow$ Krashen (1981) & aprendizagem & aquisição & \\
\hline Wilkins (1976) & planejamento situacional & planejamento nocional-funcional & \\
\hline Howatt $(1984,1988)$ & \multicolumn{2}{|c|}{ "versão fraca" (neoskinneriana) } & "versão forte" (neochomskyana) \\
\hline$\llcorner$ Brumfit (1984b) & precisão & fluência & \\
\hline Prabhu (1987) & & & $\begin{array}{l}\text { comunicacional } \\
\text { (planejamento procedimental) }\end{array}$ \\
\hline Waters (1993) & \multicolumn{3}{|c|}{ 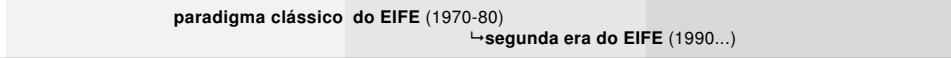 } \\
\hline Richards (1990) & abordagem direta & abordagem indireta & \\
\hline$\hookrightarrow$ Celce-Murcia et al. (1997) & \multicolumn{2}{|c|}{$\begin{array}{l}\text { abordagem indireta } \\
\text { (prática típica do ensino comunicativo nos anos de 1970-80) }\end{array}$} & $\begin{array}{l}\text { principled communicative approach } \\
\text { (1990... virada no ensino comunicativo) }\end{array}$ \\
\hline Thornbury (1998) & \multicolumn{2}{|c|}{ abordagem direta } & abordagem indireta $\rightarrow$ "uma quimera" \\
\hline Widdowson (1998) & $\begin{array}{l}\text { fins de aprendizagem/treinamento } \\
\text { (inglês para negócios/não-nativos) }\end{array}$ & $\begin{array}{l}\text { fins de uso/educação } \\
\text { (inglês de negócios/nativos) }\end{array}$ & \\
\hline Almeida Filho (1998) & funcionalizado & inocente & ultra / espontaneista \\
\hline \multirow[t]{2}{*}{$\hookrightarrow$ Almeida Filho (2004) } & \multicolumn{3}{|c|}{ abordagem comunicativa / abordagem interativo-comuncacional } \\
\hline & \multicolumn{3}{|c|}{ versões da abordagem comunicativa } \\
\hline$\hookrightarrow$ Cardoso (2002) & $\begin{array}{l}\text { 1) visão psicolinguística do } \\
\text { processamento da linguagem } \\
\text { (Halliday) }\end{array}$ & $\begin{array}{l}\text { 2) foco mensagem (Widdowson) } \\
\text { 3) ensino apropriado (Wilkins) } \\
\text { 4) comunicativa padrão }\end{array}$ & 5) práticas livres \\
\hline Howatt \& Widdowson (2004) & & $\begin{array}{l}\text { ensino comunicativo ortodoxo } \\
\text { (sociolinguística) }\end{array}$ & $\begin{array}{l}\text { linguística pós-chomskyana } \\
\text { (psicolinguística) }\end{array}$ \\
\hline Ramos (2005) & abordagem instrumental (pós $2^{\mathrm{a}} \mathrm{G}$ ) & abordagem comunicativa $(1970 \ldots$ & \\
\hline$\hookrightarrow$ Celani $(1997)$ & abordagem de EFE & abordagem comunicativa & \\
\hline Holmes \& Celani (2006) & $\begin{array}{l}\text { ESP methodology } \\
\text { (Brazilian/Latin approach) }\end{array}$ & & \\
\hline Borges $(2009,2010 a)$ & abordagem instrumental & abordagem comunicativa & abordagem comunicacional \\
\hline
\end{tabular}

\section{Instrumental e comunicativo: mesma abordagem, nomes diferentes?}

Como parte do desenvolvimento da pesquisa em Borges (2009) foi feita a seguinte pergunta (via e-mail/ internet) para alguns dos principais especialistas em ensino de línguas no contexto nacional einternacional: "Contemporaneamente, é possível falarmos em paradigmas distintos de ensino de língua quando discutimos sobre o comunicativo e o instrumental?" $\mathrm{Na}$ pesquisa em questão

\footnotetext{
${ }^{9} \mathrm{O}$ comunicacional não foi inserido, por eu acreditar na época da coleta (como acontece principalmente no contexto brasileiro) ser ele sinônimo de comunicativo, mas, devido à resposta de Prabhu - principal expoente do comunicacional -, esse contexto entra na discussão, contribuindo para uma reflexão completamente diferente da proposta inicial, como pode ser observada no desenvolvimento e evolução deste tópico e desse artigo.
} 
(como já enfatizado no final da introdução deste artigo), o uso do termo paradigma (na pergunta) se refere à noção de metaparadigma (subconjunto), que equivale à concepção de abordagem de ensino de línguas aos moldes de Anthony (1963). Outro uso do termo paradigma em Borges está relacionando a noção de movimento no ensino de línguas que na visão kuhniana se refere a paradigma sociológico (conjunto).

Responderam a essa pergunta os / as seguintes linguistas aplicados / as: Henry Widdowson (University of Vienna), Nagore Prabhu (atualmente, pesquisador independente), B. Kumaravadivelu (San Jose State Universtiy), John Swales (University of Michigan), José Carlos P. Almeida Filho (UnB), Luiz P. Moita Lopes (UFRJ), Vera Lucia M. O. Paiva (UFMG), Maria A. A. Celani (PUC/SP) e Matilde V. R. Scaramucci (UNICAMP) - todos autorizaram a divulgação de suas respostas. O QUADRO 2 a seguir traz um resumo das respostas.

\section{QUADRO 2}

Resumo das respostas de especialistas em ensino de línguas sobre o instrumental e o comunicativo em BORGES (2009)

\begin{tabular}{|c|c|}
\hline Especialistas & INSTRUMENTAL e COMUNICATIVO (comunicacional) \\
\hline Widdowson & $\begin{array}{l}\text { o comunicativo o o instrumental não são separados, são parte de um mesmo desenvolvimento; } \\
\text { o instrumental, enquanto o inglês estiver envolvido, foi de muitas formas o precursor do comunicativo como } \\
\text { uma abordagem geral de ensino de língua. }\end{array}$ \\
\hline Prabhu & $\begin{array}{l}\text { o instrumental é guiado pelo propósito de aprendizagem, com uma visão de linguagem que se adequa } \\
\text { a usos particulares; } \\
\text { o comunicativo é guiado por uma visão de linguagem como constituindo um significado ou processo de } \\
\text { comunicação; } \\
\text { o comunicacional é guiado por uma noção de que um esforço de comunicação é a condição mais favorável para } \\
\text { se adquirir uma língua; } \\
\text { - considero a posição de Widdowson e a minha como abordagens diferentes dentro de uma abordagem mais ampla. }\end{array}$ \\
\hline Kumar & o instrumentalé um tema do comunicativo. \\
\hline Swales & o instrumentale o comunicativo compartilham interesses. \\
\hline Almeida Filho & $\begin{array}{l}\text { considero dois paradigmas na teoria de ensino-aprendizagem de língua(s): o sistêmico-gramatical e o } \\
\text { comunicacional; } \\
\text { o instrumentalé parte do comunicacional. }\end{array}$ \\
\hline Moita Lopes & $\begin{array}{l}\text { o instrumentale o comunicativo possuem mesma visão de linguagem, mas diferentes propósitos de } \\
\text { aprendizagem. }\end{array}$ \\
\hline Paiva & o instrumental faz parte do paradigma da simplificação e o comunicativo do paradigma da complexidade. \\
\hline Celani & - o instrumentalé uma abordagem, e é comunicativa, o instrumental está incluído na abordagem comunicativa. \\
\hline Scaramucci & o instrumental se insere dentro de uma abordagem comunicativa. \\
\hline
\end{tabular}


Neste tópico, analiso os depoimentos apresentados no QUADRO 2, baseando-me nas reflexōes sobre esses mesmos depoimentos, já desenvolvidas de forma mais ampla em Borges (2009). Todavia, a reflexão desenvolvida aqui vai um pouco além das considerações na pesquisa em Borges, tendo em vista que insiro novas impressōes dos fatos.

Com exceção de Prabhu e Paiva, as respostas parecem convergir para a concordância de que o instrumental e o comunicativo fazem parte de uma mesma coisa: mesma abordagem, nomes diferentes? No entanto, a interpretação de tais respostas deve assumir um caráter mais cuidadoso e profundo para que se evite cair em uma simplificação do tema que, conforme foi demonstrado no tópico anterior, é bem mais complicado do que aparenta ser.

Widdowson, um dos precursores da abordagem comunicativa, compreende o instrumental e o comunicativo como parte de um mesmo desenvolvimento ou como compondo uma abordagem geral de ensino de língua, sendo o instrumental o precursor desse desenvolvimento e / ou abordagem geral. A visão de mesmo desenvolvimento e / ou de abordagem geral desse autor pode estar ligada ao que a noção de MC (como paradigma sociológico e não como abordagem comunicativa, sem o termo geral incluído) representa para a área - nos moldes apresentados em Borges (2009). Dentro dessa perspectiva, Howatt e Widdowson (2004, p. 349) já haviam enfatizado o instrumental como uma "dimensão de propósitos específicos do ensino comunicativo". Aqui, o uso do termo ensino comunicativo também pode estar se referindo à noção de $\mathrm{MC}$, enquanto que o termo dimensão pode estar se referindo à concepção de abordagem, embora os autores não explicitem esse fato. Nesse sentido, tanto a dimensão de propósitos específicos (abordagem instrumental) quanto à dimensão de propósitos gerais (abordagem comunicativa e abordagem comunicacional) comporiam o MC de ensino de línguas ou o que provavelmente Widdowson pontuou em seu depoimento como abordagem geral ou mesmo desenvolvimento.

Ao contrário de Widdowson e da maioria dos especialistas questionados, Prabhu -principal expoente do comunicacional - enfatiza diferenças importantes de fundamentação entre o instrumental, o comunicativo e o comunicacional. O primeiro é guiado pelo propósito de aprendizagem, com uma visão de que a linguagem se adapta a usos / propósitos particulares. $\mathrm{O}$ segundo é guiado por uma visão de linguagem como constituindo um significado ou processo de comunicação. O terceiro é orientado por uma visão de linguagem em que um esforço de comunicação é a condição mais favorável para adquirir uma 
lingua - visões de linguagem que entendo ser em sentido micro. Prabhu ainda coloca as posições dele e de Widdowson como abordagens diferentes dentro de uma abordagem mais ampla. $\mathrm{O}$ uso do termo abordagem mais ampla em Prabhu parece similar ao termo abordagem geral ou mesmo desenvolvimento utilizado por Widdowson, isso equivale a dizer que tanto Widdowson quanto Prabhu concordam com a noção de que há algo maior (conjunto) que abarca o instrumental e o comunicativo (subconjuntos) (WIDDOWSON), e esses e o comunicacional (PRABHU). E esse "algo maior" é possivelmente o que entendo ser o MC (conjunto / paradigma sociológico) e que se confunde na área com o termo "ensino comunicativo", "abordagem comunicativa" e ainda "competência comunicativa" (o "pacote" em HOWATT; WIDDOWSON, 2004). Da forma como Widdowson e Prabhu expuseram seus depoimentos, pode-se compreender, então, que o instrumental, o comunicativo e o comunicacional não são uma mesma coisa (mesma abordagem com nomes diferentes), mais coisas diferentes (abordagens, metaparadigmas) inseridos em um mesmo movimento, o comunicativo (o "algo maior", o paradigma sociológico).

Kumaravadivelu considera o instrumental um tema do comunicativo. Pode-se interpretar essa passagem de duas formas. Por um lado, o autor pode estar dizendo que o instrumental é algo menor que se insere na abordagem comunicativa, como um método apenas, por exemplo - porém, sabe-se que em muitos aspectos o instrumental é algo mais do que um simples método da abordagem comunicativa. Por outro lado, Kumaravadivelu pode estar se referindo ao comunicativo como movimento, o MC (o paradigma sociológico), e, aí, a visão desse autor acompanha as de Widdowson e Prabhu; ou seja, a noção de tema em Kumaravadivelu (dimensão em WIDDOWSON) corresponderia à noção de abordagem (subconjunto / metaparadigma), e a noção de comunicativo corresponderia à noção do "algo maior" (abordagem geral, mais ampla) em Widdowson e Prabhu e ao MC ou paradigma sociológico (o conjunto) em Borges (2009).

Swales, por sua vez, limita-se a dizer que o instrumental e o comunicativo compartilham interesses, o que pode aproximar a visão desse autor da noção de que ambos fazem parte do MC (paradigma sociológico / conjunto). Por esse aspecto, o comunicacional de Prabhu também compartilha os mesmos interesses dos demais, que seria, de acordo com Borges (2009), uma visão de linguagem (em sentido macro do MC / paradigma sociológico / conjunto) como ato social, mas que é diferente das visões de linguagem (em sentido 
micro) de cada contexto / abordagem (metaparadigma / subconjunto) - como ora destacado no depoimento de Prabhu, ou seja: linguagem como instrumento de comunicação (instrumental), linguagem como processo de comunicação (comunicativo) e linguagem como esforço de comunicação (comunicacional).

Entre os / as linguistas aplicados / as brasileiros / as, Almeida Filho enfatiza que o instrumental faz parte do comunicacional, e, ao mencionar o comunicacional, o autor o faz classificando-o de paradigma (em oposição ao paradigma sistêmico-funcional). A visão de paradigma do autor parece referirse à noção de movimento (paradigma sociológico / conjunto), e não de abordagem (metaparadigma / conjunto); o que leva a crer que o autor referese ao instrumental como parte do movimento comunicativo ou comunicacional, como ele prefere denominar. Lembrando que, para Almeida Filho, os termos comunicativo e comunicacional são considerados como sinônimos entre si (cf. ALMEIDA FILHO, 2004). Agora não fica claro se o comunicacional se refere também à abordagem, ou seja, se movimento comunicacional e abordagem comunicacional são a mesma coisa. Aqui, como nos outros depoimentos e na discussão apresentada no tópico anterior, fica a sensação que falta uma clareza maior na área sobre o tema em questáo. Nesse aspecto, o trabalho de Borges (2009) apresenta uma boa contribuição para o avanço das reflexões, ao separar explicitamente movimento de abordagem..$^{10}$

Moita Lopes, ao colocar que o instrumental e o comunicativo possuem mesma visão de linguagem, mas diferentes propósitos de aprendizagem, poder dar a entender que essa visão de linguagem é em sentido macro (noção de paradigma sociológico / conjunto), ou seja, visão de linguagem como ato social do MC (e não da abordagem comunicativa). Da mesma forma, ao mencionar os diferentes propósitos de aprendizagem de cada contexto, Moita Lopes pode estar se referindo às diferentes visões de linguagem em sentido micro do instrumental (linguagem como instrumento de comunicação) e do comunicativo (linguagem como processo de comunicação), conforme Prabhu destacou em seu depoimento, caracterizando-os, talvez, como abordagens distintas (metaparadigmas / subconjunto).

Paiva, em linha oposta aos demais depoimentos (com exceção do de Prabhu, que também é enfático na divisão), separa o instrumental do comunicativo como compondo paradigmas diferentes, da simplificação e $d a$

${ }^{10}$ Em Borges (2010c), separo ainda a noção de abordagem e metodologia. 
complexidade, respectivamente. Aqui, a reflexão toma um corpo mais profundo - como ocorreu também no depoimento de Almeida Filho -, já que a noção de paradigma em Paiva parece se aproximar da noção de movimento (e não da de abordagem, cf. BORGES, 2009; ou seja, da noção de paradigma sociológico, e não da de metaparadigma). E como o paradigma da simplificação é oposto ao da complexidade, o movimento oposto ao comunicativo é o gramatical (ou sistêmico-funcional, como também destaca Almeida Filho em seu depoimento) que, por sua vez, é realmente um paradigma da simplificação. Assim, por dedução da reflexão no depoimento de Paiva, o instrumental faria parte do movimento gramatical, e não do movimento comunicativo, o que, em meu entendimento, pode não ser o que Paiva quis dar a entender. Nesse sentido, Paiva poderia estar se referindo à divisão de abordagens como metaparadigmas (instrumental como a abordagem / metaparadigma da simplificação e comunicativo como a abordagem / metaparadigma da complexidade), embora não o faça explicitamente. De qualquer forma, entendo que os paradigmas da simplificação e da complexidade são diferentes paradigmas sociológicos, e não diferentes metaparadigmas.

Celani, diretamente envolvida com o instrumental no Brasil, revela que o instrumental é uma abordagem, só que é uma abordagem comunicativa. Ao colocar as palavras da forma como se apresentam, Celani - ao contrário do que possa parecer, mesmo pela perspectiva da própria linguista aplicada - pode ter respondido positivamente a pergunta que conduz o desenvolvimento deste tópico; ou seja, de que é possível, sim, reconhecer o instrumental como algo independente, como uma abordagem (como um metaparadigma). Só que o instrumental, que a própria área já é denominada de abordagem, faz parte do que se entende por comunicativo como movimento (e não comunicativo como abordagem), ou seja, faz parte do $\mathrm{MC}$, e não de outro - por isso a afirmação de Celani: é uma abordagem, e é comunicativa. A questão e / ou confusão fica por conta da insistência na área em se dizer abordagem comunicativa, referindo-se a "algo maior", ao MC. Ao fazer isso, a abordagem comunicativa - que é apenas uma abordagem (nos moldes propostos por Anthony (1963), e não um movimento nos moldes reformulados por BORGES, 2009) - ganha status de movimento e acaba colocando tudo a sua volta em um grande e único "pacote" (HOWATT; WIDDOWSON, 2004) que confunde a todos.

Por último, Scaramucci coloca que o instrumental se insere dentro de uma abordagem comunicativa. Da mesma forma, como no depoimento de 
Celani, Scaramucci parece se referir ao termo abordagem comunicativa com o significado de $\mathrm{MC}$ (paradigma sociológico), já que a autora usa, como também o faz Celani, o artigo indefinido uma em vez do artigo determinado $a$. Se o instrumental está dentro de uma abordagem comunicativa e não da abordagem comunicativa, é possivelmente devido ao fato da existência de outras abordagens "comunicativas", além da comunicativa, como a comunicacional e a instrumental, por exemplo (e outras que forem surgindo no contexto do $\mathrm{MC}$ ). Aqui, novamente, como na maioria dos depoimentos, o uso do termo abordagem comunicativa como sinônimo de MC dificulta muito o avanço das discussōes.

\section{Conclusão}

Neste artigo, pretendi mostrar que a área de ensino de línguas no Brasil e no exterior é confusa na concatenação das ideias ao tratar das abordagens de ensino de língua, principalmente ao relacionar de forma despreocupada as noções de abordagem e de movimento. Isso tanto do ponto de vista das obras de maior referência para a área, como foi mostrado no primeiro tópico deste artigo, quanto do ponto de vista de seus principais especialistas, como foi discutido no segundo tópico. Isso contraria as preocupaçôes de Anthony (1963) ao tentar "por ordem na casa", já na década de 1960, em termos de uma hierarquização terminológica (abordagem, método e técnica) para uma evolução correta das discussões, sem, contanto, mencionar o termo movimento - termo que aparece depois em função de novas demandas da área e que entendo estar acima do termo abordagem na hierarquia de Anthony. Objetivei também com este trabalho explicitar que um visível "afrouxamento" no tratamento da divisão das abordagens contemporâneas pode deixar submersa, como se fosse de pouca importância, uma questão que entendo ser primordial para se pensar a constituição e evolução da Linguística Aplicada (LA) como ciência, ou seja, a formação e desenvolvimento de paradigmas e metaparadigmas que são próprios da LA. Ainda a forma como o tema em discussão neste artigo vem sendo tratado pelos especialistas, que produz certa confusão em sua compreensão (como foi enfatizado), pode e tem consequências também para os maiores usuários desse tipo de produção científica: os professores de línguas pré e em serviço, os especialistas em linguística aplicada em formação e os elaboradores de livros didáticos e propostas pedagógico-curriculares. 


\section{Referências}

ANTHONY, E. M. Approach, method, and technique. English Teaching Forum, v. 3, n. 1, p. 7-10, 1963.

ALMEIDA FILHO, J. C. P. O professor de língua(s) profissional, reflexivo e comunicacional. Revista Horizontes de Linguistica Aplicada, v. 3, n. 1, p. 7-18, 2004.

ALMEIDA FILHO, J. C. P. Dimensões comunicativas no ensino de línguas. Campinas: Pontes, 1998.

BORGES, E. F. V. Paradigma, movimento e abordagem na LA: uma reflexão filosófica sobre a constituição da subárea ensino-aprendizagem de LE/L2 na contemporaneidade. Contexturas: Ensino Crítico de Língua Inglesa, v. 16, p. 65-93, 2010a.

BORGES, E. F. V. Comunicativo e comunicacional no ensino de línguas. Revista DELTA (Documentação de Estudos em Linguística Teórica e Aplicada), 2010 b. BORGES, E. F. V. Metodologia, abordagem e pedagogias de ensino de língua(s). Linguagem \& Ensino, v. 13, n. 2, p. 387-414, 2010c.

BORGES, E. F. V. Uma reflexão filosófica sobre abordagens e paradigmas na constituição da subárea Ensino-Aprendizagem de LE/L2 na Linguistica Aplicada. 2009. Tese (Doutorado) - Faculdade de Educação, Universidade de São Paulo, 2009.

BORGES, E. F. V. Discernimento do esteio teórico dos PCN de Lingua Estrangeira - Ensino Fundamental. 2003. Dissertação (Mestrado) - Instituto de Estudos da Linguagem, Universidade Estadual de Campinas, 2003.

BRUMFIT, C. J. Communicative methodology in language teaching: the roles of fluency and accuracy. Cambridge: Cambridge University Press, 1984.

CARDOSO, R. C. T. O imaginário do comunicativismo entre professores de língua estrangeira/inglês (e sua confrontação com teoria externa). 2002. Tese (Doutorado) - Instituto de Estudos da Linguagem, Universidade Estadual de Campinas, 2002. CELANI, M.A. Ensino de línguas estrangeiras: olhando para o futuro. In: CELANI, M. A. A. (Org.). O ensino de segunda língua: redescobrindo as origens. São Paulo: EDUC, 1997. p. 147-161.

CELCE-MURCIA, M.; DORNYEI, Z.; THURRELL, S. Direct approaches in L2 instruction: a turning point in communicative language teaching? TESOL Quarterly, v. 31, n. 1, p. 141-152, 1997.

HOLMES, J. L.; CELANI, M. A. A. Sustainability and local knowledge: the case of the Brazilian ESP Project 1980-2005. English for Specific Purposes, v. 25, p. 109-22, 2006. 
HOWATT, A. P. R. From structural to communicative. Annual Review of Applied Linguistics, v. 8, p. 14-29, 1988.

HOWATT, A. P. R. A history of English language teaching. Oxford: Oxford University Press, 1984.

HOWATT, A. P. R.; WIDDOWSON, H. G. A history of English language teaching. $2^{\text {nd }}$ ed. Oxford: Oxford University Press, 2004.

HUTCHINSON, T.; WATERS, A. English for specific purposes: a learningcentred approach. Cambridge: Cambridge University Press, 1987.

HYMES, D. On communicative competence. In: PRIDE, J. B.; HYMES, J. (Ed.). Sociolinguistics: selected readings. Harmondsworth, England: Penguin, 1972.

KRASHEN, S. D. Second language acquisition and second language learning. First internet edition, University of Southern California, 1981/2002. Disponível em: <http://www.sdkrashen.com/SL_Acquisition_and_Learning/index.html>. Acesso em: 25 jun 2010.

KRASHEN, S. D. Formal and informal linguistic environments in language learning and language acquisition. TESOL Quartely, v. 19, n. 2, p. 157-68, 1976.

KUHN, T. S. A estrutura das revoluçôes cientificas. 6. ed. Trad. Beatriz Vianna Boeira e Nelson Boeira. São Paulo: Editora Perspectiva, 1962 / 2001.

MASTERMAN, M. A natureza de um paradigma. In: LAKATOS, I.; MUSGRAVE, A. (Org.). A crítica e o desenvolvimento do conhecimento: quarto volume das atas do Colóquio Internacional sobre Filosofia da Ciência, realizado em Londres em 1965. Trad. Octavio Mendes Cajado. São Paulo: Cultrix, 1979. p. 72-108.

PALMER, H. E. The principles of language study. Londres, 1921 / 1964.

PALMER, H. E. The scientific study and teaching of languages. Londres, 1917 /1968.

PRABHU, N. S. Second language pedagogy. Oxford: Oxford University Press, 1987.

RAMOS, R. C. G. Instrumental no Brasil: a desconstrução de mitos e a construção do futuro. In: RICHARDS, J. C.; RODGERS, T. Approaches and methods in language teaching. 2. ed. Cambridge: Cambridge University Press, 2001.

RAMOS, R. C. G. Instrumental no Brasil: a desconstrução de mitos e a construção do futuro. In: FREIRE, M. M.; ABRAHĀO, M. H. V.; BARCELOS, A. M. F. Linguistica Aplicada e contemporaneidade. São Paulo: ALAB; Campinas: Pontes Editores, 2005.

RICHARDS, J. C. The language teaching matrix. Cambridge: Cambridge University Press, 1990. 
SALIMBENE, S. From structurally based to functionally based approaches to language teaching. English Teaching FORUM, v. XXI, n. 1, p. 2-7, 1983.

THORNBURY, S. Comments on Marianne Celce-Murcia, Zoltán Dörnyei, and Sarah Thurrell's "Direct approaches in L2 instruction: a turning point in communicative language teaching?” TESOL Quarterly, v. 32, n. 1, p. 109-119, 1998. WATERS, A. ESP - Things fall apart? RELC Regional Seminar. Singapore, 1993. ERIC Source. Disponível em: <http://www.eric.ed.org>. Acesso em: 15 jun. 2010.

WIDDOWSON, H. G. Communicative and community: the pragmatics of ESP. English for Specific Purpose, v. 17, n. 1, p.3-14, 1998.

WIDDOWSON, H. G. O ensino de línguas para a comunicação. Campinas: Pontes, 1978 / 1991.

WIDDOWSON, H. G. The teaching of English as communication. English Language Teaching, v. XXVII, n. 1, p. 15-19, 1972.

WILKINS, D. A. Notional Syllabuses. A taxonomy and its relevance to foreign language curriculum development. Hong Kong: Oxford University Press, 1976.

Recebido em 10/02/2011. Aprovado em 7/8/2011. 